\title{
Plant protease inhibitors as specific strategies against cancer cells
}

\begin{abstract}
Cancer is a disease that cause important mortality in the world and investigations in order to understand the mechanisms of tumor development and new treatments are crucial and are carried out in many laboratories worldwide. One of the mechanism of growth and progression of tumors is the secretion of proteases which are responsible for many processes during the cancer progression and metastasis. In this context, molecules that can inhibit these proteases are important strategies for cancer treatment. Plants are important sources of many molecules with a great diversity of functional, structural and pharmacology properties, such as, the protease inhibitors. This review addresses some aspects about molecular mechanisms of cancer proteases and some effects of plant protease inhibitors on cancer cells.
\end{abstract}

Keywords: cancer, protease, protease inhibitors, plant protease inhibitors
Volume 7 Issue 4 - 2020

\author{
Erika Maria Gomes Ferreira Teixeira, ${ }^{1,2}$ \\ Danilo Oliveira, ${ }^{2}$ Raquel Elisa Silva-López' \\ 'Departament of Natural Products, Institute of Pharmaceuticals \\ Technology, Brazil \\ ${ }^{2}$ Natural Products and Food Department, Federal University of \\ Rio de Janeiro, Brazil
}

\begin{abstract}
Correspondence: Raquel Elisa da Silva-López, Researcher of Department of Natural Products, Institute of Pharmaceuticals Technology, FIOCRUZ, Rio de Janeiro, Brazil,
\end{abstract} Email raquel.lopez@far.fiocruz.br

Received: July 19, 2020 | Published: August 24, 2020
Abbreviations: TCA, trichloroacetic acid; EMT, epithelialmesenchymal transition; ECM, extracellular matrix

\section{Introduction}

Cancer is the second cause of deaths in the world. There are more than 100 diseases that have similar features of uncontrol cell growth. Cancer cells divide rapidly, causing tumors, which can spread to other regions of the body and the different cancer types correspond to the various types of cells in the body. Many studies have shown that proteases, which are enzymes responsible for the cleavage of peptide bonds, are involved in events of growth, development, tumor progression and metastasis. They are essential for the survival of all living organisms, as they mediate signals of initiation, transmission and termination of many cellular events such as growth, development and maintenance of tissues, inflammation, apoptosis, senescence, coagulation, among others. ${ }^{1}$

\section{Tumoral proteases}

Tumors are able to stimulate the expression of proteases in normal neighboring cells, further favoring the growth of tumors. ${ }^{2,3}$ Various tumor types secrete proteases that participate in various processes related in tumor progression such as cell proliferation, due to the release of growth factors anchored to the extracellular matrix (ECM), immune responses, inflammatory cell recruitment, invasion, angiogenesis, metastasis, apoptosis, epithelial-mesenchymal transition (EMT), response to chemotherapy. Six classes of proteases may be involved in the development and invasion of cancers which are metalo, cysteine, serine, threonine, glutamic and aspartic proteases..$^{1,3,4}$ Matrix metalloproteases (MMPs) are zinc dependent endoproteases and participate in the synthesis and degradation of a wide variety of ECM components, releasing several biologically active proteins such as cytokines, growth factors and chemokines anchored in membranes. ${ }^{5}$ There are more than 25 MMPs such as collagenases, gelatinases, stromelysins, matrilysins, membrane-bound MMPs and all associated with different types of tumors. The expression of these proteases in normal tissues is low, however, is greatly increased in most of malignancies, as they have an important proteolytic action in the invasion and metastasis processes. ${ }^{6}$
Cathepsins are generally cysteine proteases found in lysosomes and perform proteolysis of both intracellular proteins and ECM proteins. They act to promote metastasis to other tissues, blood and lymph vessels. Cathepsins are usually involved with some type of tumor, being tumoral markers such as colorectal, pancreatic, carcinoma of the tongue, lung, breast, gastric, colon, head and neck carcinomas, gliomas, melanomas, as well as cancer endometrial. $., 7,8$ The activation of zymogens such as pro-MMPs and pro-cathepsins is performed by proteases of the plasminogen activator-urokinase system (uPA). It comprises two serine proteases, urokinase (uPA) and tissue plasminogen activator (t-PA), the cognate uPAR receptor and two endogenous inhibitors: the plasminogen activator inhibitor (PAI-1) and the activator inhibitor of plasminogenio II. ${ }^{9,10}$ This system also promotes the degradation of the basement membrane and other ECM components, facilitating the expansion of the tumor mass. Cancers of the breast, stomach, colorectal, esophagus, pancreas, gliomas, lung, kidney, prostate, uterus, ovary, liver and bones exhibit a direct correlation between levels of the uPA system with tumor aggressiveness and decreased survival of their hosts. This system is widely studied as a target for anti-cancer therapies, ${ }^{11}$ Other serine proteases are also crucial in the development of tumors such as Matriptase-2, a transmembrane enzyme, which in addition to degrading the components of ECM, activates the uPA system and is involved in signaling angiogenesis. ${ }^{12,13} \mathrm{~A}$ transmembrane serine protease, TMPRSS4, is related to the expressive invasive character of tumors of pancreas, ovaries, thyroid, colorectal, lung, breast, uterus, vesicle, stomach and liver. ${ }^{14}$ Trypsin is the most well-known serine protease and is involved in many physiological and pathological processes. She is involved in processes of proliferation, invasion and metastasis in colorectal cancer. ${ }^{15,16}$ Digestion of type II collagen by trypsin promotes invasion of the basement membrane. In addition, the activation of trypsin in tumor cells and the co-expression of MMPs facilitate invasion and metastasis. ${ }^{17} \mathrm{Hepsin}$ or TMPRSS1 is a transmembrane serine protease found mainly in the kidney, pancreas, stomach, prostate and thyroid and its levels are elevated in prostate, breast, ovary, kidney and endometrial cancers. The representative of aspartic proteases is cathepsin D (CATD), which is an important endoproteinase involved in different physiological processes and signaling pathways. It is one of the main proteins secreted in different 
types of cancers, being present in its microenvironments, where it has been seen to increase its expression and secretion in cancers such as ovarian, breast, endometrial cancer, lung cancer, malignant glioma, melanoma and prostate cancer. Many studies show that the presence of this protease increases the capacity for invasion and the risk of metastasis. ${ }^{19,20}$

\section{Protease inhibitors in cancer}

Protease inhibitors (PIs) are molecules that bind in a specific way at the active site or elsewhere in the enzyme, interfering with catalysis, interrupting or decreasing the cleavage reactions of peptide bonds. The vast majority of natural PIs have one or more polypeptide chains and can be found in plants, microorganisms and animals that control the activity of their target proteases. They can be classified according to the type of proteases that they inhibit in serine, cysteine, aspartic and metalloprotease inhibitors. ${ }^{21}$ As previously reported, proteases are extremely important in the development, growth of cancers, and can be targeted for drug development. In this way, its specific inhibitors, can be seen as possible anti-cancer agents, acting in the inhibition of these enzymes. MMPs are inhibited by tissue inhibitors of mammalian metalloproteases, TIMPs. They are proteins of 184-194 amino acids with $21 \mathrm{kDa}$. They are: TIMP-1, TIMP-2, TIMP-3 and TIMP-4, each of which inhibits the activity of MMPs with different catalytic efficiencies. ${ }^{1,22}$ The altered expression of TIMPs shows that they have an important role in tumor environment. Many studies have shown that the high expression of TIMP-1 is associated with a poor prognosis of cancer in the lung, brain, prostate, breast, colon and several other cancers. This expression may be a tissue response to functionally high protease activity in the tumor microenvironment. This inhibitor is being studied as a future biomarker for recognizing or monitoring the response to patients' treatment. Differently, TIMP3 expression is reduced in many types of cancers, being associated with the advanced stage in colorectal, breast, brain and bladder cancer. TIMP-2 and TIMP-4 can be more or less expressed depending on the type of cancer and the stage of the disease. ${ }^{23}$

Some MMP-inhibiting drugs have been developed, such as Batimastate and marimastate. Batimastate is a peptideomimetic MMP inhibitor that showed high inhibitory activity against MMPs. But this medicine showed, orally, low bioavailability. Marimastate has advanced to phase 2 and 3 clinical trials for different tumors, such as pancreas, lung, breast, colorectal, brain and prostate. Despite this, the drug caused joint pain, stiffness and inflammation in patients, which forced them not to continue their studies. ${ }^{24}$ The family of cysteine protease inhibitors, cystatins, appears to have important blocking activity for tumor metastasis and invasion, as they inhibit cathepsins $\mathrm{B}, \mathrm{H}$ and $\mathrm{L}$ which are known for their great importance in the growth, development and metastasis of tumors. ${ }^{25-27}$ Cystatins A and B, or Stefans A and B, are markers of aggressive tumors that appear in much lower concentrations than in normal individuals. ${ }^{28,29}$

In normal cells, matriptases (serine proteases) are inhibited by hepatocyte growth factor activator inhibitor-1 (HAI-1) and it has been observed that in prostate cancer, there is a decrease in HAI-1 and increased expression of these proteases. Serpin, inhibitors of serine proteases, are used as markers of colorectal, lung and prostate cancers and inhibit tumor growth and lung cancer angiogenesis. ${ }^{13} \mathrm{As}$ can be seen, tumor cells modulate the activity of proteases involved in extracellular proteolysis, MMPs and uPA/uPAR/plasminogen. In addition, the increase in different tumor proteases, results in the degradation of ECM, the growth of tumors (by releasing growth factors), metastases, angiogenesis, among other events. Therefore, PIs can be considered crucial strategies in anti-cancer therapy, and it is necessary to search for new PIs that inhibit proteases involved with cancers. ${ }^{1}$

\section{Plant protease inhibitors}

Plants are known sources of a huge diversity of molecules, and are also a great source of PIs. Vegetables are susceptible to changes in environmental conditions and, therefore, synthesize molecules for their protection, among them small molecules such as secondary metabolites and larger molecules of primary metabolism, polypeptides, often PIs. ${ }^{30,31}$ They are important in defense against pests, insects and even pathogens because they are induced in plants through attacks by insects or pathogens. In insects, they interfere in the digestion process because they have the ability to inhibit their digestive proteases. They are low molecular weight polypeptides that are very stable at variations in temperature and $\mathrm{pH} .{ }^{32}$ Plant PIs (PPIs) are found in plants of various systematic groups in particular from species of the Fabaceae or Leguminosae family and accumulate in the seeds, but are also observed in other plant organs. They represent the largest group of plant PIs and their main families include: Kazal, Kunitz, Tomato, Cereal, Soy trypsin inhibitor, Squash, Bowman-Birk, Potato and Serpinas. PPIs have two main functions: mobilization of nutrients such as essential amino acids, peptides and proteins by blocking the degradation of storage proteins in seeds, and protecting the plant from attack by pests by inhibiting their digestive enzymes. These PPIs could have different biological activities and, therefore, are considered as innovative alternatives in the treatment, control and prevention of different types of diseases..$^{33,34}$ As mentioned before, PIs have many biological functions and they have been investigated as potential strategies for different pathologies, as in different types of cancers. PPIs have been isolated and characterized for several years and have been shown to be good therapeutic agents. ${ }^{35}$ Studies in animal models have shown that the ingestion of legumes rich in BowmanBirk family inhibitors (BBI), such as soy, peas, lentils and chickpeas, and the ingestion of the isolated inhibitor prevented and suppressed carcinogenic and inflammatory processes ofgastrointestinal tract. ${ }^{34}$ The table 1 shows some PPIs and their activity against tumor cells of different types of cancers.

\section{PPIs (Plant protease inhibitors) extraction}

Plant cells are made up of several compounds, including a set of polysaccharides, which makes them difficult to break down. The first step in the preparation of a plant extract rich inproteins, is the disruption of this tissue. It is performed by spraying with grade and pistil using liquid nitrogen. This method reduces the degradation of proteins in the vegetal tissues by minimizing proteolysis and other types of degradation. The finer the powder produced, the more proteins are extracted later (Figure 1A). ${ }^{59,60}$ Finally, the extraction of proteins is a difficult stage to choose because of the enormous diversity of structural characteristics among plants. There are many protocols for the extraction of proteins for each type of plant and plant tissue and extractions with water and aqueous buffers can be used. ${ }^{32-59}$ The extraction using phenol and trichloroacetic acid (TCA) showed high yield of protein extraction. In addition, extraction by protein precipitation with TCA and acetone can also be used. Another method used is extraction with buffered phenol ( $\mathrm{pH} 8.0$ buffer) followed by precipitation with methanol. 
Table I Plant protease inhibitors with potential application against cancer cells

\begin{tabular}{|c|c|c|c|}
\hline Name & Origen & Activity & Reference \\
\hline $\mathrm{BBI}$ & Glycine max $L$. & $\begin{array}{l}\text { Reduced the proliferation of colon adenocarcinoma cell } \\
\text { lines }\end{array}$ & $36,37,38$ \\
\hline KTI & Glycine max $L$. & $\begin{array}{l}\text { Inhibited uPA urokinase activity of human ovarian cancer } \\
\text { cells, decreasing their invasion }\end{array}$ & 39,40 \\
\hline BbKI & Bauhinia bauhinioides & $\begin{array}{l}\text { Inhibited plasma kallikrein, bovine trypsin, chymotrypsin. } \\
\text { Decreased pulmonary edema in rabbits }\end{array}$ & 41,43 \\
\hline - & Bauhinia rufa & $\begin{array}{l}\text { Inhibited plasma kallikrein, bovine trypsin and decreased } \\
\text { pulmonary edema in rabbits }\end{array}$ & 42,43 \\
\hline - & Cicer arietinum $L$. & $\begin{array}{l}\text { Decreased the viability of brain cancer and prostate cancer } \\
\text { cells }\end{array}$ & 44 \\
\hline - & Cocciniagrandis & Inhibited the growth of colon cancer cell lines & 45 \\
\hline - & Elusinecoracana & $\begin{array}{l}\text { Reduced cellular proliferation and induced apoptosis of } \\
\text { myeloid leukemia cell and not was cytotoxic to human } \\
\text { peripheral blood mononuclear cells }\end{array}$ & 46 \\
\hline EcTI & Enterolobiumcontortilisiliquum & $\begin{array}{l}\text { Inhibited cancer lineages as colloretal, leukemia, breast and } \\
\text { prevented proMMP activation }\end{array}$ & 47 \\
\hline $\begin{array}{l}\text { LC-pi I, II, } \\
\text { III, and IV }\end{array}$ & Lavatera cashmerianaCamb. & $\begin{array}{l}\text { Demonstrated in vitro anticancer activity on leukemia, lung, } \\
\text { and colon cells }\end{array}$ & 48 \\
\hline LCTI & Lens culinaris & Inhibited cell growth of colon adenocarcinoma & 49 \\
\hline MsTI & Medicago scutellata $L$. & Citotoxic to breast and cervical carcinoma cells & 50,51 \\
\hline TBPI & $\begin{array}{l}\text { Phaseolus acutifolius A. and Phaseolus } \\
\text { vulgaris } L \text {. }\end{array}$ & $\begin{array}{l}\text { Decreased cell invasion capacity, extracellular matrix } \\
\text { degradation and suppressed of MMP-9 }\end{array}$ & 52 \\
\hline FBPI & Viciafaba L. & $\begin{array}{l}\text { Suppressed skin carcinogenesis and stopped pulmonary } \\
\text { metastasis of melanoma cells }\end{array}$ & 53,54 \\
\hline BTCl & Vigna unguiculata & Affected breast cells & 55,56 \\
\hline CrataBL & Crataeva tapia Bark & Inhibited U87 cell invasion and adhesion & 57 \\
\hline CC-PI & Cajanuscajan & Inhibited cell growth of adenocarcinomic human alveolar & 58 \\
\hline
\end{tabular}
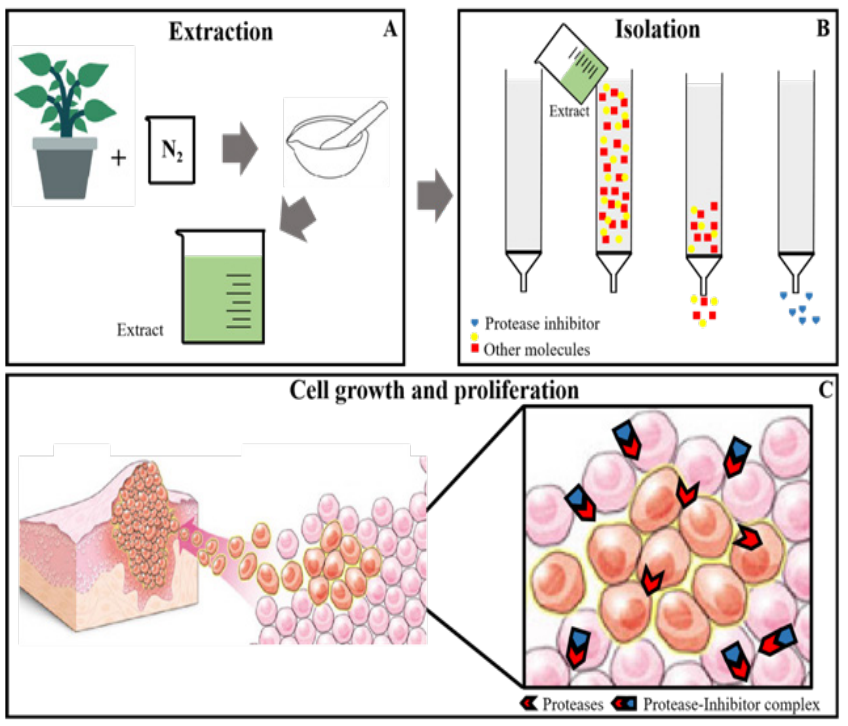

Figure I PPIs obtaining:The first step is preparation of extract, plant organ is sprayed with grade and pistil in $\mathrm{N}_{2}$, the proteins in the powder are extracted with different extracting agents $(A)$; isolation and purification is performed with chromatographic techniques (B) and these purified PPIs are evaluated for their biological activity $(C)$.
Many methods of isolating and purifying proteins from protein extracts can be used andchromatography is the method of choice (Figure 1B\&1C). This technique is use for separating, identifying and purifying mixtures of substances through the interaction between these substances between the mobile phase and the stationary phase. The most employed chromatographies are: affinity, ion exchange and gel filtration. Affinity chromatography is based on the principle of biological affinity, where the protein is isolated according to its function. The specific ligand for the protein to be isolated will be coupled in the stationary phase and they will interact. Those remaining molecules (which are not of interest) are eluted with the stationary phase. ${ }^{45,46}$ Molecular exclusion chromatography (or filtration gel) is based on a separation in which smaller molecules penetrate the pores of the stationary phase, taking longer to be excluded and larger ones do not penetrate these pores, having a migration speed greater, being excluded first. ${ }^{45,48,52,58}$ The ion exchange chromatography occurs through the ionic bond that occurs between the charged molecules of the complex sample and the stationary phase, which has an opposite charge. ${ }^{45,47,52,56}$

\section{Conclusion}

The investigation of new compounds for cancer treatment is 
an important challenge in worldwide public health. The proteases are paramount in cancer progression, because they are involved in tumor nutrition, digestion of ECM to release growth factors and facilitate proliferation and metastasis. Consequently, their specific inhibitors can be effective to discontinue tumor cells growth, and could be employed as important agents in the chemotherapy of a great variety of neoplasms. Many plants PIs are polypeptides widely research for a great diversity of cancers, such as breast and colorectal adenocarcinomas. These natural peptides have shown effectiveness, specificity and safety molecules in comparison to the most aggressive and small synthetic molecules recommended for cancer treatments. These PIs bond specifically by multiple points at the active sites of tumor proteases and block the cancer progression. Thus, this review shows the importance of studying these molecules as potential strategies for controlling the growth of cancers.

\section{Acknowledgments}

None.

\section{Conflicts of interest}

The author declares that there is no conflict of interest.

\section{Funding}

None.

\section{References}

1. Eatemadia A, Aiyelabegana HT, Negahdaria B, et al. Role of protease and protease inhibitors in cancer pathogenesis and treatment. Biomedicine \& Pharmacotherapy. 2017;86:221-231.

2. Rakashanda S, Ishaq M, Masood A, et al. Antibacterial activity of a trypsin-chymotrypsin-elastase inhibitor isolated from Lavatera cashmeriana camb. Seeds Journal of Animal Plant Science. 2012;22:983-986.

3. Chang J, Chaudhuri O. Beyond proteases: Basement membrane mechanics and cancer invasion. Journal of Cell Biology. 2019;218:24562469 .

4. Mason D, Joyce JA. Proteolytic networks in cancer. Trends in Cell Biology. 2011;21:228-237.

5. Pittayapruek P, Meephansan J, Prapapan O, et al. Role of matrix metalloproteinases in photoaging and Photocarcinogenesis. International Journal of Molecular Science. 2016;17:868.

6. Gong Y, Chippada-Venkata UD, Oh WK. Roles of matrix metalloproteinases and their natural inhibitors in prostate cancer progression. Cancers. 2014;6:1298-1327.

7. Mohamed MM, Sloane BF. Cysteine cathepsins: multifunctional enzymes in cancer. Nature Review Cancer. 2006;6:764-775.

8. Olson OC, Joyce JA. Cysteine cathepsin proteases: regulators of cancer progression and therapeutic response. Nature Reviews Cancer. 2015;15:712-729.

9. Mekkawy AH, Morris DL, Pourgholami MH. Urokinase plasminogen activator system as a potential target for cancer therapy. Future Oncology. 2009;5:1487-1499.

10. Kelley LC, Chi Q, Cáceres R. Adaptive F-Actin polymerization and localized ATP production drive basement membrane invasion in the absence of MMPs. Developmental Cell. 2019;48:313-328.

11. Su S, Lin C, Yang C, et al. The urokinase-type plasminogen activator
(uPA) system as a biomarkerand therapeutic target in human malignancies. Expert opinion on therapeutic targets. 2016;20;1-16.

12. Sanders AJ, Webb SL, Parr C, et al. The type II transmembrane serine protease, matriptase-2: possible links to cancer? Anti-cancer agents in medicinal chemistry. 2010;10:64-69.

13. Zuo K, Qi Y, Yuan C, et al. Specifically targeting cancer proliferation and metastasis processes: the development of matriptase inhibitors. Cancer and Metastasis Reviews. 2019;38:507-524.

14. Aberasturi AL, Calvo A. TMPRSS4: an emerging potential therapeutic target in cancer. British Journal of Cancer. 2015;112:4-8.

15. Yamamoto H, Iku S, Adachi Y. Association of trypsin expression with tumour progression and matrilysin expression in human colorectal cancer. Journal of Pathology. 2003;199:176-184.

16. Yan R, Liu M, Hu Y. Ectopic expression of human airway trypsin $\square$ like protease 4 in acute myeloid leukemia promotes cancer cell invasion and tumor growth. Cancer Medicine. 2019;8:2348-2359.

17. Nyberg P, Moilanen M. Paju A. MMP-9 activation by tumor trypsin-2 enhances in vivo invasion of human tongue carcinoma cells. Journal of Dental Research. 2002;81:831-835.

18. Murray AS, Varela FA, List K. Type II transmembrane serine proteases as potential targets for cancer therapy. Biological Chemistry. 2016;397:1-25.

19. Pranjol ZI, Gutowski N, Hannemann M, et al. The potential role of the proteases cathepsin D and cathepsin L in the progression and metastasis of epithelial ovarian cancer. Biomolecules. 2015;5:3260-3279.

20. Dubey V, Luqman S. Cathepsin D as a promising target for the discovery of novel anticancer agents. Curr cancer drug targets. 2017;17:404-422.

21. Hellinger R, Gruber CW. Peptide-based protease inhibitors from plants. Drug Discovery Today. 2019;24:1877-1889.

22. Jackson HW, Defamie V, Waterhouse P, et al. TIMPs: versatile extracellular regulators in cancer. Nature reviews-cancer. 2014;14:632641 .

23. Cui N, Hu M, Khalil RA. Biochemical and biological attributes of matrix metalloproteinases. Progress in Molecular Biology Translacional Science. 2017;147:1-73.

24. Winer A, Adams S, Mignatti P. Matrix metalloproteinase inhibitors in cancer therapy: Turning past failures into future successes. Molecular Cancer Therapeutics. 2018;17:1147-1155.

25. Folgueras AR, Pendás AM, Sánchez LM, et al. Matrixmetalloproteinases in cancer: from new functions to improved inhibition strategies. The International Journal of Developmental Biology. 2004;48:411-424.

26. Cox JL. Cystatins and cancer. Frontiers in Bioscience. 2009;14:463-74.

27. Breznik B, Mitrović A, Lah T, et al. Cystatins in cancer progression: More than just cathepsin inhibitors. Biochimie. 2019;166:233-250.

28. Zajc I, Sever N, Bervar A, et al. Expression of cysteine eptidase cathepsinL and its inhibitors stefins A and B in relation to tumorigenicity of breastcancer cell lines. Cancer Letters. 2002;187:185-190.

29. Butinar MT, Prebanda J, Rajkovic B. Stefin B deficiency reduces tumor growth via sensitization of tumor cells to oxidative stress in a breast cancer model. Oncogene. 2014;33:3392-3400.

30. Silva-López RE. Proteases inhibitors originated from plants: useful approach for development of new drug. Revista Fitos. 2009;4:108-119.

31. Gomes MTR, Oliva ML, Lopes MTP, et al. Plant proteinases and inhibitors: An overview of biological function and pharmacological activity. Current Protein and Peptide Science. 2011;12:417-436. 
32. Shamsi TN, Parveen R, Fatima S. Characterization, biomedical and agricultural applications of protease inhibitors: a review. International Journal of Biological Macromolecules. 2016;91:1-54.

33. Bateman KS, James MNG. Plant protein proteinase inhibitors: Structure and mechanism of inhibition. Current Protein and Peptide Science. 2011;12: 41-347.

34. Clemente A, Arques MC. Bowman-Birk inhibitors from legumes as colorectal chemopreventive agents. World Journal of Gastroenterol. 2014;20:10305-10315.

35. Srikanth S, Chen A. Plant protease inhibitors in therapeutics-focus on cancer therapy. Frontiers in Pharmacology. 2016;7:1-19.

36. Kennedy AR. The status of human trials utilizing Bowman-Birk inhibitor concentrate from soybeans. Soy in Health and Disease Prevention. 2006.

37. Chan AT, Baba Y, Sima K. Cathepsin B expression and survival in colon cancer: implications for molecular detection of Neoplasia. Cancer Epidemioogy, Biomarkers \& Prevention. 2010;19:2777-2785.

38. Fereidunian A, Sadeghalvad M, Oscoie MO, et al. Soybean BowmanBirk protease inhibitor (BBI): Identification of the mechanisms of BBI suppressive effect on growth of two adenocarcinoma cell lines: AGS and HT29. Archives of Medical Research. 2014;45:455-461.

39. Kobayashi H, Suzuki M, Kanayama N, et al. A soybean Kunitz trypsin inhibitor suppresses ovarian cancer cell invasion by blocking urokinase upregulation. Clinical \& Experimental Metastasis. 2004;21:159-166.

40. Kobayashi H. Prevention of Cancer and Inflammation by Soybean Protease Inhibitor. Frontiers in Bioscience. 2013;1:966-973.

41. Oliva ML, Andrade SA, Batista IF. Human plasma kallikrein and tissue kallikrein binding to a substrate based on the reactive site of a factor Xa inhibitor isolated from Bauhinia ungulata seeds. Immunopharmacology. 1999;45(1-3):145-149.

42. Nakahata AM, Bueno NR, Rocha HA. Structural and inhibitory properties of a plant proteinase inhibitor containing the RGD motif. International Journal of Biological Macromolecules. 2006;40(1):2229.

43. Neuhof C, Oliva ML, Maybauer D. Effect of plant kunitz inhibitors from Bauhinia bauhinioides and Bauhinia rufa on pulmonary edema caused by activated neutrophils. The Journal of Biological Chemistry. 2003;384:939-944

44. Magee PJ, Owusu-Apenten R, Mccann MJ, et al. Chickpea (Cicer arietinum) and other plant-derived protease inhibitor concentrates inhibit breast and prostate cancer cell proliferation in vitro. Nutrition and Cancer. 2012;64:741-748.

45. Satheesh LS, Murugan K. Antimicrobial activity of protease inhibitor from leaves of Coccinia grandis (L.) Voigt. Indian Journal of Experimental Biology. 2011;49:366-374.

46. Sen S, Dutta SK. Evaluation of anti-cancer potential of rag bifunctional inhibitor (RBI) from Elusine coracana on human chronic myeloid leukemia cells. The European Journal of Plant Science and Biotecnology. 2012;6:103-108.
47. Nakahata AM, Mayer B, Rie C. The effects of a plant proteinase inhibitor from Enterolobium contortisiliquum on human tumor cell lines. The Journal of Biological Chemistry. 2011;392:327-336.

48. Rakashanda S, Mubashir S, Qureshi Y. Trypsin inhibitors from Lavatera cashmeriana Camb. seeds: isolation, characterization and in-vitro cytotoxity activity. International Journal of Pharmaceutical Science Invention. 2013;2:55-65.

49. Caccialupi P, Ceci LR, Siciliano RA. Bowman-Birk inhibitors in lentil: Heterologous expression, functional characterisation and anti-proliferative properties in human colon cancer cells. Food and Chemistry. 2010;120:1058-1066.

50. Catalano M, Ragona L, Molinari H, et al. Anticarcinogenic Bowman Birk inhibitor isolated from snail medic seeds (Medicago scutellata) solution structure and analysis of self-association behaviour. Biochemistry. 2003;42:2836-2846.

51. Lanza A, Tava A, Catalano M. Effects of the Medicago scutellata trypsin inhibitor (MsTI) on cisplatin-induced cytotoxicity in human breast and cervical cancer cells. Anticancer Research. 2004;24:227-234.

52. García-Gasca T, García-Cruz M, Hernandez-Rivera E. Effects of tepary bean (Phaseolus acutifolius) protease inhibitor and semipure lectin fractions on cancer cells. Nutrition and Cancer. 2012;64(8):1269-1278.

53. Fernandes AO, Banerji AP. The field bean protease inhibitor can effectively suppress 7,12-dimethylbenz[a]anthracene-induced skin tumorigenesis in mice. Cancer Letters. 1996;104(2):219-224.

54. Banerji A, Fernandes A, Bane S, et al. The field bean protease inhibitor has the potential to suppress B16F10 melanoma cell lung metastasis in mice. Cancer Letters. 1998;129:15-20.

55. Souza C, Camargo R, Demasi M, et al. Effects of an anticarcinogenic Bowman-Birk Protease Inhibitor on Purified 20S Proteasome and MCF7 Breast Cancer Cells. PLoS ONE. 2014;9:1-10.

56. Mehdad A, Brumana G, Souza AA. A Bowman-Birk inhibitor induces apoptosis in human breast adenocarcinoma through mitochondria impairment and oxidative damage following proteasome $20 \mathrm{~S}$ inhibition. Cell Death Discovery. 2016;2(15067).

57. Bonturi CR, Silva MCC, Motaln H. A Bifunctional molecule with lectin and protease Inhibitor Activities Isolated from Crataeva tapia Bark Significantly Affects Cocultures of Mesenchymal Stem Cells and Glioblastoma Cells. Molecules. 2019;24(11):(2109).

58. Shamsi TN, Parveen R, Ahamad S, et al. Structural and biophysical characterization of Cajanus cajan protease inhibitor. Journal of Natural Science, Biology and Medicine. 2017;8(2):186-192.

59. Gonçalves RN, Barbosa SDG, Silva-López RE. Proteases from Canavalia ensiformis: active and thermostable enzymes with potential of application in biotechnology. Biotechnology Research International. 2016:3427098.

60. Giavalisco P, Nordhoff E, Lehrach H, et al. Extraction of proteins from plant tissues for two-dimensional electrophoresis analysis. Electrophoresis. 2003;24:207-216. 